\title{
BROADBAND STUDY OF THE 1989 LOMA PRIETA EARTHQUAKE
}

\author{
Hiroo Kanamori and Kenji Satake
}

\begin{abstract}
We determined the source characteristics of the Oct. 18, 1989 Loma Prieta, California, earthquake using teleseismic data. The solution from body waves gives a mechanism with $\operatorname{dip}=70^{\circ}$, rake $=138^{\circ}$, and strike $=128^{\circ}$, and a seismic moment of $3 \times 10^{26}$ dyne-cm $\left(M_{w}=6.9\right)$. This solution is similar to those obtained from long-period Rayleigh and Love waves, $\mathrm{P}_{\mathrm{nL}}$ waves, and first-motion data. The body wave form suggests a depth of about $15 \mathrm{~km}$. The effective duration of the source is $6 \mathrm{sec}$, which suggests a fault length of $30 \mathrm{~km}$ and $15 \mathrm{~km}$ for bilateral and unilateral faulting, respectively. Considering the extent of the aftershock area, we used $35 \mathrm{~km}$ as an estimate of the total rupture length. The strike-slip and the thrust components of the coseismic slip are 177 and $159 \mathrm{~cm}$, respectively. The large thrust component raises an important question regarding the recurrence pattern. If the Loma Prieta earthquake is a characteristic earthquake with a recurrence interval of about 100 years, the $159 \mathrm{~cm}$ displacement implies a long term uplift rate of about $1 \mathrm{~cm} /$ year, which appears too large for this region. Three hypotheses for reconciling this apparent conflict are: (1) the geometry of plate motion along the Santa Cruz Mountain segment changes over a time scale of several thousand years so that the coseismic displacement has not accumulated enough to produce high topographic relief; (2) the coscismic slip direction varies from event to event; (3) the slip plane of the 1989 Loma Prieta earthquake is different from the major boundary between the Pacific and the North American plates; if this is the case, the Loma Prieta earthquake is a rather rare non-characteristic event. The surface slip of about $1 \mathrm{~m}$ for the 1906 San Francisco earthquake is one of the key data in long-term forecasting. No surface slip was observed for the 1989 Loma Prieta earthquake, even if the horizontal slip at depth is as large as $1.8 \mathrm{~m}$. This points to a risk of relying too heavily on surface observations for long-term seismic risk analysis.
\end{abstract}

\section{Introduction}

The Oct. 18, 1989 Loma Prieta, California, earthquake (00:04:15.2 GMT; $\left.37.036^{\circ} \mathrm{N}, 121.883^{\circ} \mathrm{W}, 19 \mathrm{~km}\right)$ occurred in a seismic gap which had been identified as the one with a higher than 30 percent (in 30 years) probability of producing an earthquake with $M=6.5$ to 7 [Lindh, 1983; Scholz, 1985; Sykes and Nishenko, 1984; Working Group on California Earthquake Probabilities, 1988]. This forecast is based on the historical seismicity and low background seismicity in this gap, and the amount of surface break (about $1 \mathrm{~m}$ ) for the 1906 San Francisco earthquake. Thatcher and Lisowski[1987] argue, however, on the basis of the geodetic data, that the coseismic slip for the 1906 earthquake was about $2.6 \mathrm{~m}$ so that it will take more than 150 years to accumulate this amount of slip (a long-term slip rate of $1.5 \mathrm{~cm} /$ year is assumed for the San Andreas fault in this region), which implies that a large earthquake is unlikely in the next few decades.

Now that the Loma Prieta earthquake has occurred, it is

Copyright 1990 by the American Geophysical Union. important to assess how this earthquake compares with the published forecast. To this end, we analyzed seismic data, primarily very broadband seismograms, to determine the source characteristics of this event. The data used in this study are summarized in Table 1.

Table 1. Stations and Data Used

\begin{tabular}{lcccl}
\hline Station & $\begin{array}{c}\Delta \\
\text { (deg.) }\end{array}$ & $\begin{array}{c}\phi \\
\text { (deg.) }\end{array}$ & $\begin{array}{c}\phi_{\mathrm{B}} \\
\text { (deg.) }\end{array}$ & Phases Used \\
\hline ARU & 86.9 & 360 & 0 & $\mathrm{P}, \mathrm{SH}, \mathrm{R}_{1}, \mathrm{G}_{1}$ \\
OBN & 85.4 & 12 & 343 & $\mathrm{P}, \mathrm{SH}, \mathrm{R}_{1}, \mathrm{G}_{1}$ \\
SSB & 84.9 & 35 & 320 & $\mathrm{P}$ \\
HRV & 38.6 & 66 & 279 & $\mathrm{P}, \mathrm{SH}, \mathrm{R}_{1}, \mathrm{G}_{1}$ \\
WFM & 38.6 & 66 & 279 & $\mathrm{P}, \mathrm{SH}$ \\
ANMO & 12.6 & 95 & 284 & $\mathrm{R}_{1}, \mathrm{G}_{1}$ \\
CAY & 70.7 & 99 & 307 & $\mathrm{P}, \mathrm{SH}$ \\
RPN & 64.9 & 168 & 349 & $\mathrm{P}, \mathrm{SH}, \mathrm{R}_{1}, \mathrm{G}_{1}$ \\
PPT & 60.3 & 211 & 25 & $\mathrm{P}, \mathrm{SH}$ \\
KIP & 35.0 & 254 & 56 & $\mathrm{SH}$ \\
\hline
\end{tabular}

\section{Mechanism}

Since the most complete data we could obtain are broadband data from the IRIS (Incorporated Research Institution for Seismology) and GEOSCOPE stations, we first describe the source mechanism obtained from these data. In this analysis, all the seismograms are deconvolved to ground motion displacements. The data are shown in Figure 1. We used the method developed by Kikuchi and Kanamori[1989] to invert these records and determine the mechanism. The observed seismograms are matched by synthetics computed for a sequence of subevents distributed on a fault plane. Green's functions for five independent moment tensor elements are computed, and the subevents are represented by a linear combination of them. By minimizing the difference between the observed and synthetic seismograms, we determine the moment tensor or mechanism of all the subevents as well as their spatial location and timing.

Since many free parameters are involved in this type of inversion, trade-offs between different source parameters could occur. First we used a very simple model to obtain the overall model. We used a single source with a trapezoidal time function $\left(t_{1}, t_{2}\right)$ as shown in Figure 1 . We varied $t_{1}$ and $t_{2}$ to obtain the best solution. The structure shown in Table 2 is used for both the source and receiver structures (common to all the stations). The attenuation time constant $t^{*}=1$ and $4 \mathrm{sec}$ and weights of 3 and 1 are used for $P$ and $S$ waves, respectively. We tried three discrete depths, 10,15 , and $20 \mathrm{~km}$, and obtained the best fit at $15 \mathrm{~km}$. The inversion resulted in $t_{1}=2.5$ $\mathrm{sec}, \mathrm{t}_{2}=5 \mathrm{sec}$, seismic moment of $\mathrm{M}_{0}=2.4 \times 10^{26} \mathrm{dyne}-\mathrm{cm}$, and the focal mechanism given by $\left(\operatorname{dip}=70^{\circ}\right.$, rake $=138^{\circ}$, strike $\left.=128^{\circ}\right)$. Although this is a very simple source, it explains the overall feature of the observed wave form, and the residual (observed-synthetic) wave forms are very small.

In Kikuchi and Kanamori's[1989] method, the inversion obtains successive point sources to fit the residual wave 
Observed (top) and Synthetic(bottom) Wave Forms

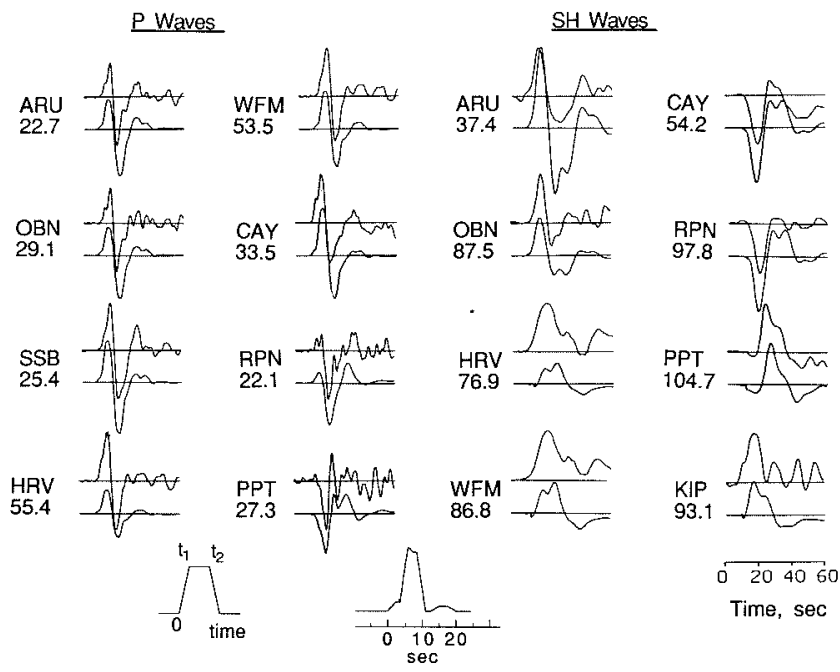

Fig. 1. Observed (top) and synthetic (bottom) seismograms for the 1989 Loma Prieta earthquake. All the records show ground motion displacement. The numbers under the station codes are the absolute displacement amplitudes (the distance between the base line to either the peak or the trough of the observed record, whichever is larger) in $\mu$. The trapezoidal source function and the time function for the 3-event source are shown at the bottom. The stations are arranged in increasing order of clockwise azimuth from the north. The mechanism is shown in Figure 2.

forms. In our case, the first point source explains most of the data so that the other point sources are relatively small.

We assumed that the mechanism of all the subevents is the same as that of the first one, and inverted the data. Since the later events are small and their significance is questionable, we consider the first two or three events with a total seismic moment of 2.9 or $3.1 \times 10^{26}$ dyne-cm, respectively. Figure 1 compares the synthetic wave forms for the three-event model with the observed. Because of the noise in the data, especially the significant site response at some of the stations (e.g. KIP), the decision on where to terminate the sequence (iteration in the inversion) is inevitably subjective. If we include all the subevents, the total seismic moment increases considerably. Considering the total seismic moment obtained from longperiod waves (to be described later), we consider a seismic moment significantly larger than $3 \times 10^{26}$ dyne-cm unrealistic. In the later section, we use a rounded value of $3 \times 10^{26}$ dyne$\mathrm{cm}$ for the seismic moment for this event. From body-wave data alone, any value between 2.5 and $3.5 \times 10^{26}$ dyne-cm is acceptable. The result is summarized in Table 3 and Figure 2.

Although the effective duration of the principal subevent is $5 \mathrm{sec}$ (Figure 1), we estimated an effective duration to be 6 $\mathrm{sec}$, allowing for the contributions from the smaller subevents.

Table 2. Source and Receiver Structures

\begin{tabular}{cccc}
\hline$\alpha(\mathrm{km} / \mathrm{sec})$ & $\beta(\mathrm{km} / \mathrm{sec})$ & $\rho\left(\mathrm{g} / \mathrm{cm}^{3}\right)$ & $\mathrm{H}(\mathrm{km})$ \\
\hline 5.5 & 3.18 & 2.6 & 4 \\
6.3 & 3.64 & 2.67 & 23.4 \\
6.8 & 3.93 & 2.8 & 5.0 \\
8.0 & 4.64 & 3.2 & -- \\
\hline
\end{tabular}

Table 3. Summary of the Results

\begin{tabular}{lcllllll}
\hline \multicolumn{1}{c}{ Data } & $\mathrm{M}_{0}{ }^{*}$ & $\delta_{1}$ & $\lambda 1$ & \multicolumn{1}{c}{$\phi_{1}$} & $\delta 2$ & $\lambda_{2}$ & $\phi_{2}$ \\
\hline P and $\mathrm{SH}$ & 3 & 70 & 138 & 128 & 51 & 26 & -125 \\
Surface Waves & 2.5 & 70 & 137 & 128 & 50 & 26 & -124 \\
$\mathrm{R}_{1}$ and $\mathrm{G}_{1}$ & 2.8 & $70 \dagger$ & 144 & 129 & 57 & 24 & -127 \\
$\mathrm{P}_{\mathrm{nL}}$ & 2.9 & 75 & 130 & 125 & 42 & 23 & -129 \\
\hline & & & & & & &
\end{tabular}

†fixed.

We used Kawakatsu's[1989] method and inverted longperiod surface waves to determine the source centroid mechanism (i.e. CMT solution). In this inversion, both the fundamental-mode and overtone Love and Rayleigh waves are used. The pass band of the filter is from 3.5 to $7 \mathrm{mHz}$. The result is shown in Table 3 and Figure 2.

In order to examine the possible increase in the seismic moment at long period, we inverted surface waves at a period of $256 \mathrm{sec}$ separately using the method described by Kanamori and Given[1981]. In this inversion, the dip angle of one of the nodal planes $\left(70^{\circ}\right)$ is fixed to avoid instability in the inversion. The mechanism is shown in Figure 2. The seismic moment is $2.8 \times 10^{26}$ dyne-cm, which is essentially the same as the bodywave and the CMT solutions. No evidence is found for the increase in the seismic moment with period.

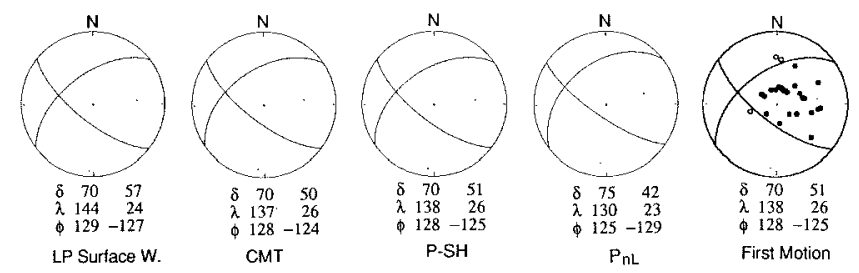

Fig. 2. Mechanism diagrams for the 1989 Loma Prieta earthquake obtained from data sets with different periods. Symbols $\delta, \lambda$, and $\phi$ are dip, rake and strike of the two nodal planes (in degrees) respectively. The nodal planes shown with the first motion data are taken from the solution obtained from P-SH data. The period decreases from left to right.

The first motion data shown in Figure 2 are consistent with the body-wave and CMT solutions.

Woods et al. [1990] used $\mathrm{P}_{\mathrm{nL}}$ waves recorded at Pasadena and determined the mechanism by matching the wave forms with synthetics. Their preferred solution is shown in Table 3 and Figure 2.

As shown in Table 3 and Figure 2, the mechanisms obtained from data sets with different periods are essentially the same, and the seismic moment determined from body waves (period, about $10 \mathrm{sec}$ ) is about the same as that determined from surface waves with a period of $256 \mathrm{sec}$, which suggests a simple source for the Loma Prieta earthquake.

The estimated seismic moment is $3 \times 10^{26}$ dyne-cm, which gives $\mathbf{M}_{\mathbf{w}}=6.9$.

\section{Source Duration and Rupture Length}

Figure 1 shows that the effective duration of the source is about $6 \mathrm{sec}$, which can be used to infer the rupture length. If the rupture is unilateral, the effective duration $\tau$ is given by $\tau=(\mathrm{L} / \mathrm{V})-(\mathrm{L} \cos \Theta / \mathrm{c})$ where $\mathrm{L}$ is the rupture length, $\mathrm{V}$ the 
rupture velocity, $\Theta$ the azimuth of the station measured from the rupture direction, and $c$ is the body wave phase velocity along the free surface. Since the $\mathrm{P}$ wave phase velocity is much faster than the rupture velocity, the second term is much smaller than the first. Hence, the rupture length is approximately $\mathrm{L}=\mathrm{V} \tau=15 \mathrm{~km}$, if $\tau=6 \mathrm{sec}$ and $\mathrm{V}=2.5 \mathrm{~km} / \mathrm{sec}$. If the rupture is bilateral, the rupture length is about twice that for the unilateral case, i.e. $30 \mathrm{~km}$.

The main shock is located near the center of the aftershock area [U.S.G.S. staff, 1990], which suggests bilateral faulting. If the fault rupture is bilateral, our estimate of the effective duration, $6 \mathrm{sec}$, suggests, $L=30 \mathrm{~km}$. The total length of the aftershock area is about $40 \mathrm{~km}$ [U.S.G.S. staff, 1990]. Although teleseismic data cannot resolve the details of the slip distribution on the fault, it is almost certain that the rupture length does not exceed the length of the aftershock area. In the following calculations, we use $\mathrm{L}=35 \mathrm{~km}$, but a shorter rupture length is not precluded.

\section{Complexity}

As shown by Figure 1, the source process of the Loma Prieta earthquake is very simple. Figure 3 compares the displacement wave form of the Loma Prieta earthquake with that of the 1988 Armenian earthquake $\left(M_{W}=6.7\right)$, recorded at HRV. Comparison at other stations exhibits essentially a similar difference. Figure 3 suggests that the duration of the Armenian earthquake is $40 \mathrm{sec}$ or even longer, which is in striking contrast to that of the Loma Prieta earthquake, about 6 sec. Pacheco et al.[1989] suggest a substantial variation of
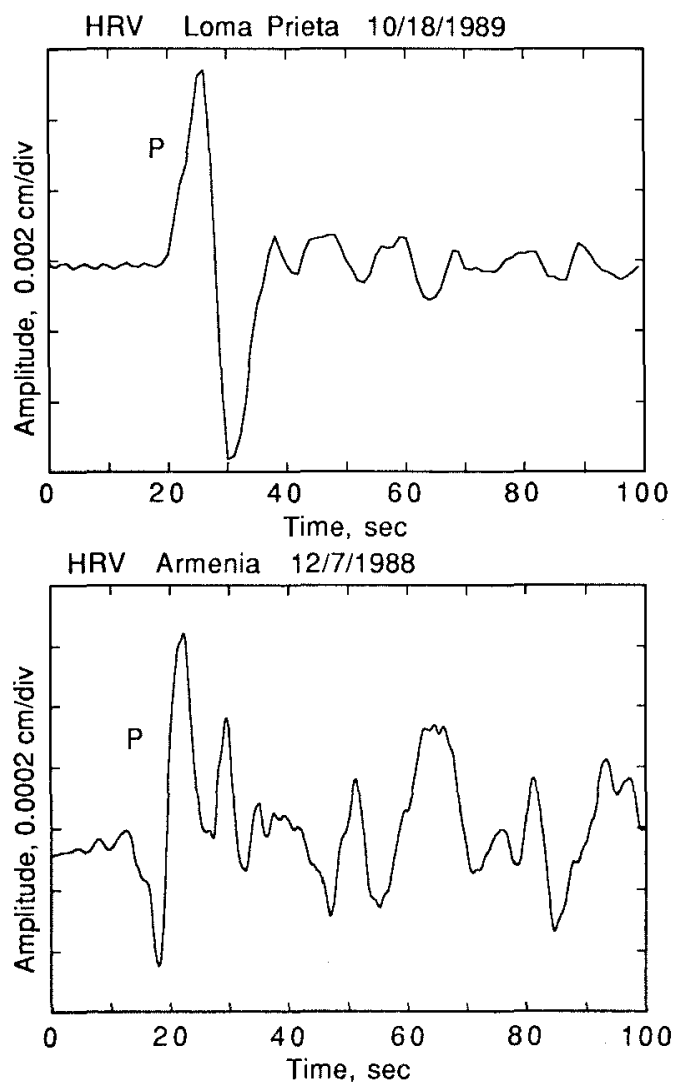

Fig. 3. Comparison of the displacement records of the 1989 Loma Prieta and the 1988 Armenian earthquakes recorded at HRV. focal mechanisms during the first $10 \mathrm{sec}$ of the Armenian earthquake.

This comparison clearly demonstrates the simplicity of the source process of the Loma Prieta earthquake which involved a relatively short segment along the fault. This difference in source complexity may have a profound influence on the damage potential of the earthquake. Although it is generally agreed that the heavy damage caused by the Armenian earthquake is primarily due to poor construction of the buildings, the source complexity and long duration are very likely to have contributed to the heavy damage as well. Since the source complexity is closely related to the local tectonic structure, earthquakes with the same magnitude as the Loma Prieta earthquake in different tectonic environments can be more damaging than the Loma Prieta earthquake.

\section{Coseismic Slip}

If we assume the fault length $\mathrm{L}$, the fault width $\mathrm{W}$, and the rigidity to be $35 \mathrm{~km}, 12 \mathrm{~km}$, and $3 \times 10^{11} \mathrm{dyne} / \mathrm{cm}^{2}$ respectively, we obtain a coseismic slip of $238 \mathrm{~cm}$ from the estimated seismic moment of $3 \times 10^{26}$ dyne-cm. The strike-slip and the thrust components of the displacement are 177 and 159 $\mathrm{cm}$, respectively. The average stress drop is estimated to be approximately 50 bars.

\section{Discussion and Conclusion}

Two aspects of this earthquake are noteworthy: the thrust component as large as $159 \mathrm{~cm}$, and the short rupture length, only $35 \mathrm{~km}$, for an $\mathrm{M}_{\mathrm{w}}=6.9$ earthquake.

The large thrust component, $1.6 \mathrm{~m}$, raises an important question regarding the recurrence pattern of the earthquakes along the Santa Cruz Mountain segment.

The long term forecast of the Loma Prieta earthquake is based upon the combination of historical seismicity, estimated slip rate of the San Andreas fault along the Santa Cruz Mountain segment, and the surface slip (about $1 \mathrm{~m}$ ) for the 1906 San Francisco earthquake [Lindh, 1983; Sykes and Nishenko, 1984; Scholz, 1985]. Implicit in this forecast is a relatively short recurrence interval, about 80 to 100 years. If the Loma Prieta earthquake is a characteristic earthquake to be expected along this section of the San Andreas with a recurrence interval of about 100 years, the thrust component of $1.6 \mathrm{~m}$ during the Loma Prieta earthquake implies a long-term uplift rate of about $1 \mathrm{~cm} /$ year, which is comparable to the largest rate observed in the world [e.g. Yonekura, 1983]. An uplift rate this large is usually associated with spectacular topographic relief. Although the long-term uplift rate in the epicentral area is not known, the regional geomorphological feature does not seem to be in line with such a high rate. We present three hypotheses to reconcile this apparent conflict.

The first hypothesis is that the geometry of plate motion along the Santa Cruz Mountain segment of the San Andreas fault changes on a time scale of several thousand years so that the coseismic vertical displacement has not accumulated enough to produce a high topographical relief. In this case, the Loma Prieta earthquake can be considered a characteristic earthquake along this segment on this time scale.

The second hypothesis is that the coseismic slip direction varies from event to event. For example, for the 1906 San Francisco earthquake, it is possible that the slip along this segment was essentially strike slip, having been driven by much larger strike-slip displacements along the adjacent segment. Even for the earlier events which involved the Santa 
Cruz Mountain segment only, the slip could have been primarily strike slip, if sufficient stress had not accumulated there to cause vertical displacement.

The third hypothesis is that the slip plane of the 1989 Loma Prieta earthquake is different from the major plate boundary between the Pacific and the North American plates; in this case the Loma Prieta earthquake is a rather rare event and not a characteristic event along the San Andreas fault. Although no obvious geological evidence exists, this possibility cannot be ruled out.

The short rupture length, about $35 \mathrm{~km}$, of the Loma Prieta earthquake is very anomalous in the light of the empirical data available for shallow crustal earthquakes, as shown in Figure 4. In fact, the magnitude estimate of the forecasted event is based on the empirical relation such as that shown in Figure 4. For example, Scholz[1985] identified a $75 \mathrm{~km}$ long slip-deficit segment along the Santa Cruz Mountain segment, and forecasted an $M=6.9$ earthquake. Lindh[1983] identified a 35 $\mathrm{km}$ gap and associated it with an $\mathrm{M}=6.5$ earthquake. These estimates are consistent with the empirical relation shown in Figure 4. The anomalous fault length-moment relationship for the Loma Prieta earthquake is the cause of discrepancy between the forecasted and the actual events.

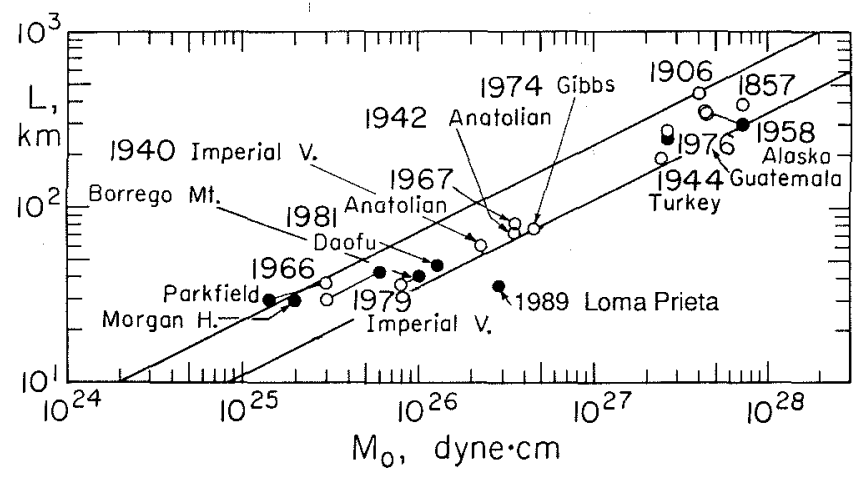

Fig. 4. The relation between the fault length and seismic moment for shallow crustal earthquakes along active plate boundaries. The base figure is taken from Kanamori and Magistrale[1989]. The two solid lines indicate the range of the data points.

The surface slip of about $1 \mathrm{~m}$ during the 1906 San Francisco earthquake is one of the key data in the long-term forecast. Thatcher and Lisowski[1987] argue, however, that the slip of $2.4 \mathrm{~m}$ at depth determined from geodetic data should be used for estimating long-term probability. No surface slip was observed for the 1989 Loma Prieta earthquake, even if the horizontal slip at depth is as large as $1.8 \mathrm{~m}$. This discrepancy points to a risk of relying too heavily on the surface observations for long-term seismic risk analysis.

The case for the long-term forecast of the Loma Prieta earthquake testifies the importance of synthesizing seismological, geological, geodetic, and historical data to obtain probabilistic parameters for long-term hazard assessment and planning. The quantitative analysis of modern seismological data revealed many important details such as the source complexity, fault geometry, and rupture length which, in conjunction with the probabilistic parameters, provide key information for implementing effective seismic hazard reduction measures.
Acknowledgment. We benefited from discussions with Don Helmberger throughout this study. We thank Holly Given and Barbara Romanowicz for having provided us with key data from IDA/IRIS and GEOSCOPE stations. Some of the first-motion data were provided by Laura Jones. This work was partially supported by the U.S. Geological Survey grants 14-08-0001-G1773 and 14-08-0001-G1832. Kenji Satake is supported by the Fellowship for Research Abroad from the Japan Society for the Promotion of Science. Contribution number 4846, Division of Geological and Planetary Sciences, California Institute of Technology, Pasadena, California.

\section{References}

Kanamori, H., and H. Magistrale, State of stress in seismic gaps along the San Jacinto fault, in Observatory Seismology, edited by J. J. Litehiser, pp. 179-186, University of Califomia Press, London, 1989.

Kawakatsu, H., Centroid single force inversion of seismic waves generated by landslides, J. Geophys. Res., 94, 12363-12374, 1989.

Kikuchi, M., and H. Kanamori, Analysis of multiple events with mechanism changes, abstract, Seismol. Soc. Japan, page 3, No. 1, 1989.

Lindh, A. G., Preliminary assessment of long-term probabilities for large earthquakes along selected segments of the San Andreas fault system in California, U.S.G.S., Open File Rep., 83-63, 1-15, 1983.

Pacheco, J. F., C. H. Estabrook, D. W. Simpson and J. L. Nabelek, Teleseismic body wave analysis of the 1988 Armenian earthquake, Geophys. Res. Lett., 16, 14251428, 1989.

Scholz, C. H., The black mountain asperity: Seismic hazard of the southern San Francisco peninsula, California, Geophys. Res. Lett., 12, 717-719, 1985.

Sykes, L. R., and S. P. Nishenko, Probabilities of occurrence of large plate rupturing earthquakes of the San Andreas, San Jacinto and Imperial faults, California, J. Geophys. Res., 89, 5905-5927, 1984.

Thatcher, W., and M. Lisowski, Long term seismic potential of the San Andreas fault southeast of San Francisco, U.S. Geological Survey Staff, The Loma Prieta, California, earthquake: An anticipated event, Science, 247, 286-293, 1990.

Woods, B. B., L-S. Zhao, D. V. Helmberger, H. K. Thio, and H. Kanamori, The Loma Prieta earthquake sequences as observed at Pasadena, Geophys. Res. Lett., submitted, 1990.

Working Group on California Earthquake Probabilities, Probabilities of large earthquakes occurring in California on the San Andreas fault, U.S. Geological Survey Open-File Report 88-398, 62 pages, 1988.

Yonekura, N., Late Quaternary vertical crustal movements in and around the Pacifics deduced from former shoreline data, in Geodynamics of the western Pacific-Indonesian region, Geodynamics Series, II, edited by T. Hilde and S. Uyeda, American Geophysical Union and Geological Soc. Am., Washington, D.C., 1983.

H. Kanamori and K. Satake, Seismological Laboratory, California Institute of Technology, Pasadena, CA 91125.

(Received February 26, 1990; Accepted April 11, 1990) 